\title{
Effect of Electrodes Separation in DC Plasma Sputtering on Morphology of Silver Coated Samples.
}

\author{
Khalid A. Yahya ${ }^{1}$ and Ban F. Rasheed \\ Department of Physics, College of Science, Al-Nahrain University, Baghdad-Iraq. \\ E-mail: drkayahya2005@yahoo.com.
}

\begin{abstract}
In this work, the effect of the electrodes separation on plasma parameters and morphology properties for coated glass samples by silver metal using low voltage DC discharge plasma sputtering source. At fixed argon gas pressure 0.2 mbar and discharge currents $I_{d}(20,30,40,50$ and $60) \mathrm{mA}$, for different electrodes separation $\mathrm{d}(3,4,4.5,5,6) \mathrm{cm}$ was studied. The plasma sputtering source consists of a cylindrical chamber including two circular electrodes made from stainless steel. The cathode electrode is carrying the silver metal as a target and permanent magnet, while a glass sample coater is placed on the anode electrode. The plasma parameters: temperature of electron $\left(\mathrm{T}_{\mathrm{e}}\right)$ and ion density $\left(\mathrm{n}_{\mathrm{i}}\right)$ were determined by using cylindrical single Langmuir probe. Also, the surface morphology for the coater samples were studied by atomic force microscope (AFM). The results of this work shown that a linear increases in ions density and an exponential decreasing in electron temperature for different electrodes separation. Furthermore, the relationship between the average grain diameter and average grain height as a function of electrodes separation are nonlinear. The minimum average grain diameter is $(90 \mathrm{~nm})$ at $\mathrm{d}=4 \mathrm{~cm}$ for $\mathrm{I}_{\mathrm{d}}=40 \mathrm{~mA}$ and minimum average grain height is $(5.5 \mathrm{~nm})$ at the same electrodes separation and discharge current. When the temperature of electron increased, the values of average grain diameter increased while the values of average grain height decreased.
\end{abstract}

Keyword: Langmuir probe, surface morphology, magnetron sputtering, DC discharge.

\section{1- Introduction}

Cold plasma technologies have found a widely field used in different applications such as, in material processing, manufacture of thin film material, medicine and industrial process [1-5].

The magnetic field is widely used which caused enhancement of some attractive features for discharge in plasma source [6,7].

Sputtering process is one of the most common ways to fabricate thin films, nanostractured, coating and nanoparticle of various materials $[8,9]$.

The basic process for production particles as follows: A target (cathode) of material desired to be deposited, is bombarded with energetic ions. Then, the target atoms are ejected into the space and travel some distance until they reach the substrate and formed a thin layer.

In magnetron sputtering a higher plasma density and deposition rates can be achieved by using a magnetic field which confines the motion of secondary electrons near the cathode surface (target). Furthermore, an applied of magnetic field is caused for enhancing the efficiency and quality of deposited films at lower inert gas pressure $[10,11,12]$.

Generally, a DC power supply is usually used to sputter conducting target, while RF power supply is required for insulator or semiconductor target $[13,14]$.

In the present work, different electrodes separations for planar DC magnetron plasma coater low voltages were investigated to determine the effects of this variation on the electrical characteristics discharge, plasma diagnostics and the morphology of silver coater on glass substrate by using a constant argon inert gas pressure.

\section{2- Experimental setup}

Fig.(1) shows a schematic diagram of the experimental setup. The cylindrical discharge chamber is a Borosilicate glass tube of $127 \mathrm{~mm}$ length and $165 \mathrm{~mm}$ diameter. Two parallel, circular electrodes made of stainless steel are enclosed in the discharge chamber. The anode (stage of substrate) is made of stainless steel with a diameter $50 \mathrm{~mm}$ and the cathode of silver with a diameter $57 \mathrm{~mm}$ and $0.1 \mathrm{~mm}$ thick as a target according to the 
sputtering purposes. A permanent cylindrical magnet is placed in the center of cathode electrode to produce the magnetic field. The discharge chamber is evacuated to a base pressure of $1 \times 10^{-2}$ mbar by using two-stage rotary pump. The argon working pressure is fixed of 0.2 mbar. A vacuum gauge (Pirani gauge) is connected to the chamber for measuring the inside gas pressure. The DCpower supply is used for discharging argon gas varied between (0-800)volt and (0-100)mA. A single cylindrical Langmuir probe made of tungsten wire of $0.5 \mathrm{~mm}$ diameter, and $8 \mathrm{~mm}$ length is used to characterize the plasma parameters. The probe is positioned perpendicular to the electric field near the cathode (target) of $15 \mathrm{~mm}$. The DC power supply varied between (0-450)volt and $(0-150) \mathrm{m} \mathrm{A}$ is used in the probe circuit as a positive and negative bias voltage for probe. Using Hall probe (Alpha lab Inc./USA) to measured Magnetic flux for radial distance from the edge to edge for cathode passing through the center of the magnet, and for axial distance between cathode and anode electrodes. The surface morphology information collected by using AFM(AA2000, Angstrom Advanced Inc./USA).

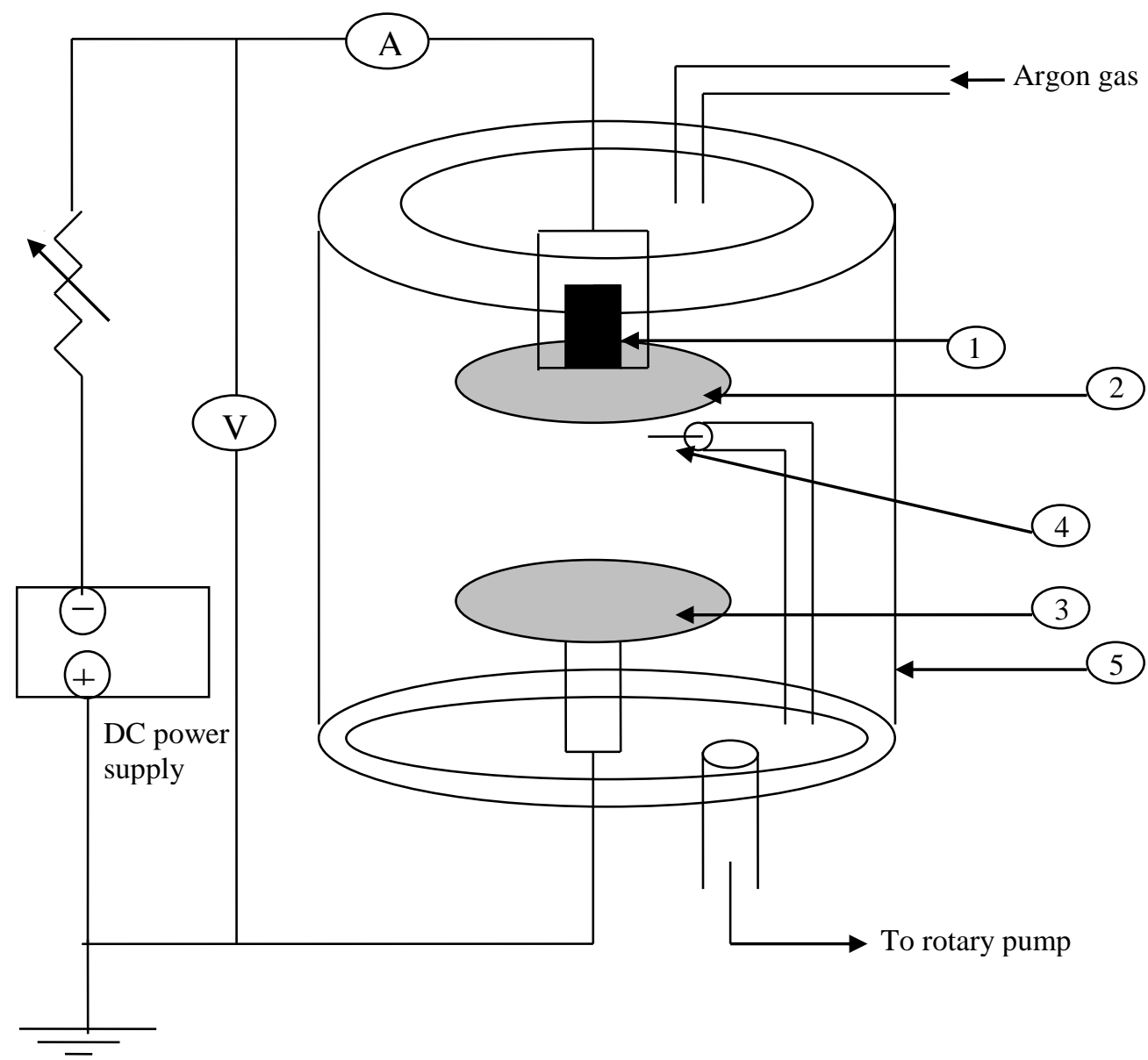

Fig. (1): Schematic diagram of the experimental setup

1- Permanent magnets. 2-Cathode (silver target). 3- Anode electrode. 4- Langmuir probe. 5- Discharge chamber.

\section{3-Results and Discussion}

\section{3-1 Distribution of the magnetic field strengths}

Fig.(2-a) shows the radial distribution of the magnetic flux density, $\mathrm{B}$, as measured across the cathode electrode diameter. This figure shows that the magnetic flux density is not uniform. The magnetic flux has maximum value (3350 Gauss) in the center cathode region, and then the flux decrease at the edge of the cathode. The axial distribution of $B$ along the discharge tube at a distance between cathode and anode electrode is shown in Fig.(2-b). The magnetic flux density has a 
maximum value at the center of the cathode fall region, and then it decreased at anode center.
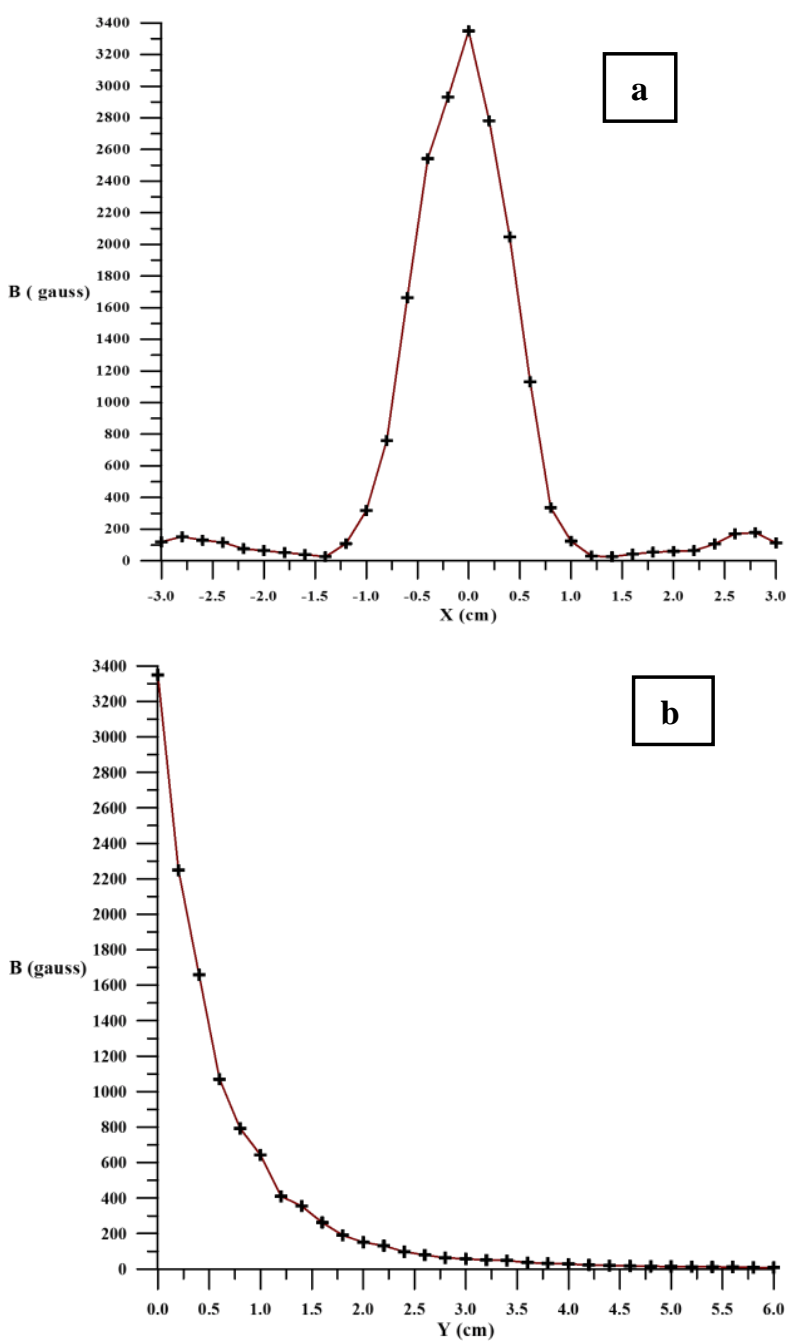

Fig.(2): Magnetic flux distribution for aradial distance from the edge to edge for cathode electrode passing through the center of the magnet. $b$-axial distance between cathode and anode electrodes.

\section{3-2 Effect of electrodes separation on I-V characteristic of DC discharge}

The variation of discharge current (sputtering current) on cathode electrode, $\mathrm{I}_{\mathrm{d}}$, with applied cathode DC voltage $\mathrm{V}_{\mathrm{c}}$ of discharge tube for different electrodes separation $(3,4,4.5,5$ and 6$) \mathrm{cm}$ at fixed argon gas pressure $\mathrm{P}(0.2$ mbar $)$ with silver target are shown in Fig.(3). It is shown that as the discharge current increases, the cathode voltage increased with increasing the separation between electrodes. Furthermore, the effects of increased electrodes separation are clear on increased cathode voltage.
On the other hand, the same behaviors were obtained for electron current (current which is measuring at anode electrode), $\mathrm{I}_{\mathrm{a}}$, as a function of discharge current is shown in Fig.(4).

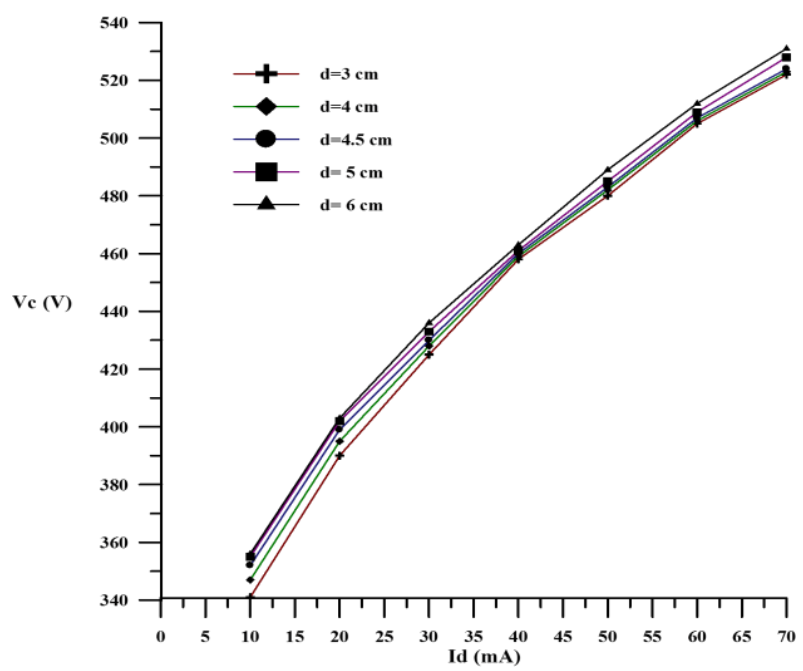

Fig.(3): Voltage of cathode electrode as a function of sputtering current at $P=0.2 \mathrm{mbar}$ for different electrodes separation.

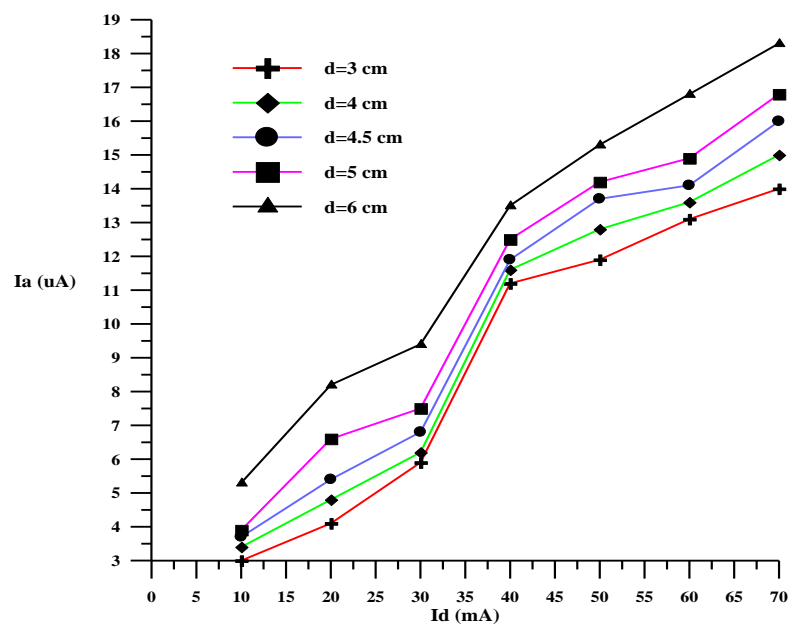

Fig.(4): Anode current as a function of sputtering current at $P=0.2$ mbar for different electrodes separation.

\section{3-3 Effect of electrodes separation on} plasma parameters

Knowing the plasma parameters such as, electron temperature and plasma density nearby the cathode sheath is very important to describe the behaviors of DC magnetron coater [5]. Also, these parameters are effected on the positive ion flux towards the surface and the morphology of the growing films. In this work, a cylindrical Langmuir probe is used to determine temperature of electron and ion density (see Fig.(1)). 
Langmuir probe I-V characteristics are measured for different separation of electrodes at fixed argon gas pressure, as shown in Fig.(5).

It is noticed from Fig.(5) that when the probe is negatively biased all electrons are repelled and the ions are accelerated to the probe, and it is a nearly constant value, called the ion saturation current. As the applied voltage is increased most high energy electrons are able to travel down the potential gradient to be collected by the probe which acts as electron retarding regime. The temperature of electron $\mathrm{T}_{\mathrm{e}}$ are calculated from the inverse slope of the logarithmic plot of the electron retarding regime as shown in Fig.(6) using the relation [15]

$$
\mathrm{d} \ln \mathrm{I}_{\mathrm{p}} / \mathrm{dV}_{\mathrm{p}}=\mathrm{e} / \mathrm{k}_{\mathrm{B}} \mathrm{T}_{\mathrm{e}}
$$

Where $I_{P}$ is the probe current, $V_{P}$ is the probe voltage, $\mathrm{k}_{\mathrm{B}}$ is Boltzmann's constant and e is electron charge.

Fig.(7) shows the temperature of electron as a function of electrode separation $d$ at fixed argon pressure 0.2 mbar using silver target .As the electrode separation increases, more collisions occur, the kinetic energy loss through electron inelastic collisions with atom increases, thus the electron temperature decreases .

Another plasma parameter, ion density $n_{i}$, can be calculated corresponding to orbital motion limit theory (OML) [15]

$$
I_{i}=A_{p} n_{i} e \frac{\sqrt{2}}{\pi}\left(-e V_{p} / m_{i}\right)^{1 / 2}
$$

Where $I_{i}$ is the ion current, $A_{P}$ is the probe area and $\mathrm{m}_{\mathrm{i}}$ is the mass of ion. By plotting a line fit for the square ion current as a function of probe voltage, the slope from this figure is used to calculate the ion density for different electrodes separation by using equation (3)

$$
n_{i}=\left(\sqrt{8 m_{i}} / e \sqrt{e}\right)\left[(\text { slope })^{1 / 2} / A_{p}\right]
$$

Where, slope $=\mathrm{I}_{\mathrm{i}}^{2} / \mathrm{V}_{\mathrm{p}}$ and $\mathrm{m}_{\mathrm{i}}$ is the ion mass.

The ion densities as a function of electrodes separation are shown in Fig.(8). It is noticed that the density of ions are increased as increased the electrodes separation. This behavior are due to increasing the probability of collisions which causes increasing the ionization of gas atoms by confinement electrons and obtaining a high sputtering rate of target atoms.

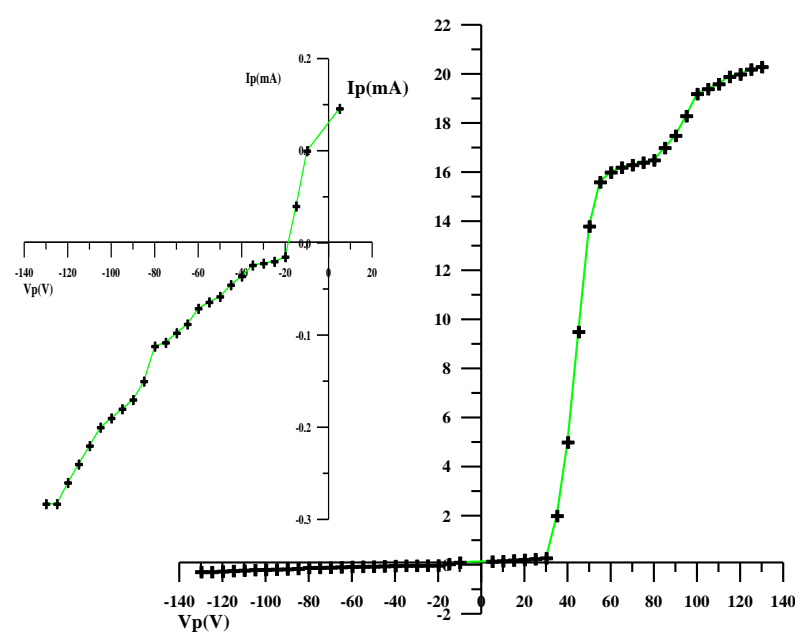

Fig.(5): I-V characteristics curve of Langmuir probe for argon discharge at $I_{d}=40$ $m A, d=4 \mathrm{~cm}$.

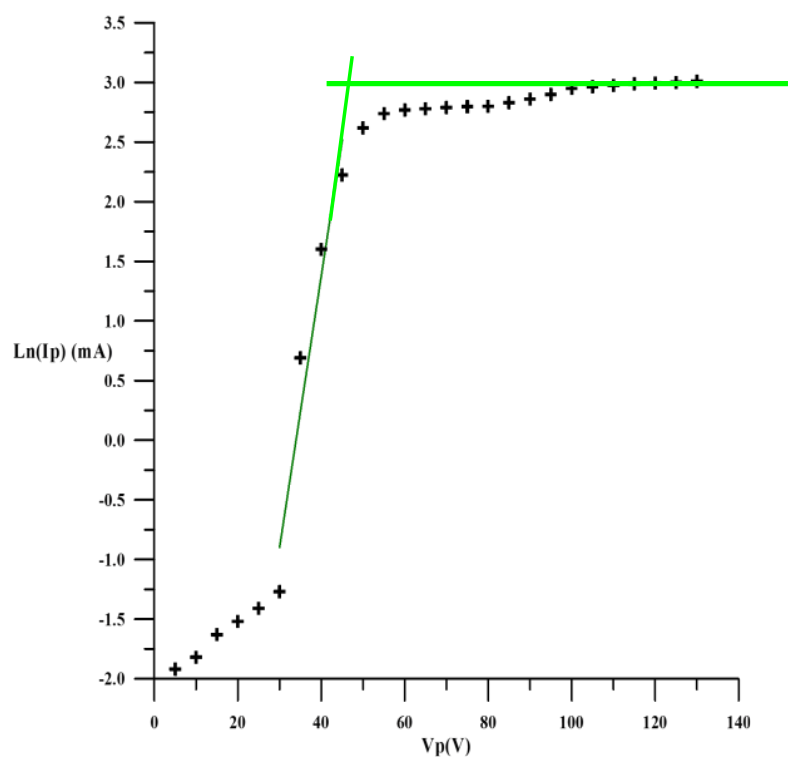

Fig.(6): Variation of $\operatorname{Ln}(\mathrm{Ip})$ as a function of probe voltage at $I_{d}=40 \mathrm{~mA}, d=4 \mathrm{~cm}$. 


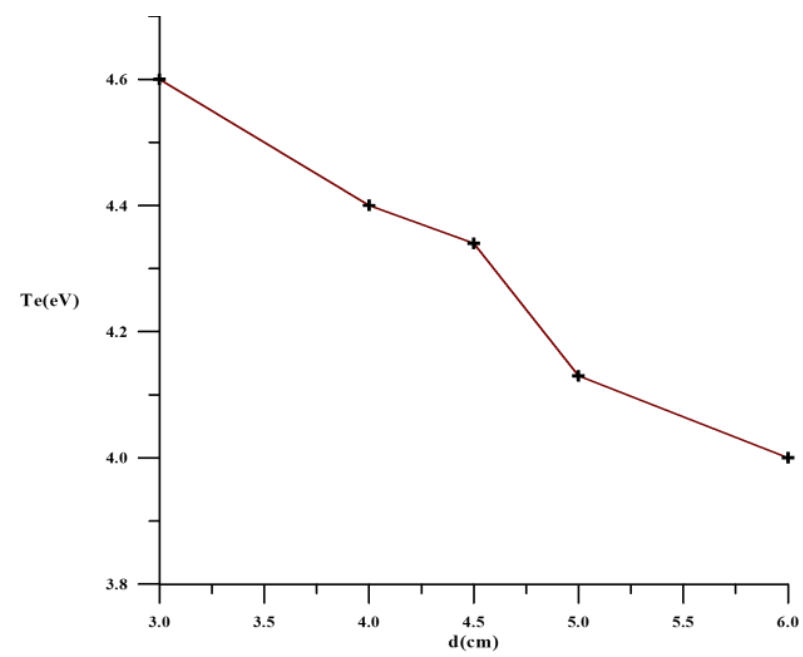

Fig.(7): Variation of electron temperature as a function of electrodes separation.

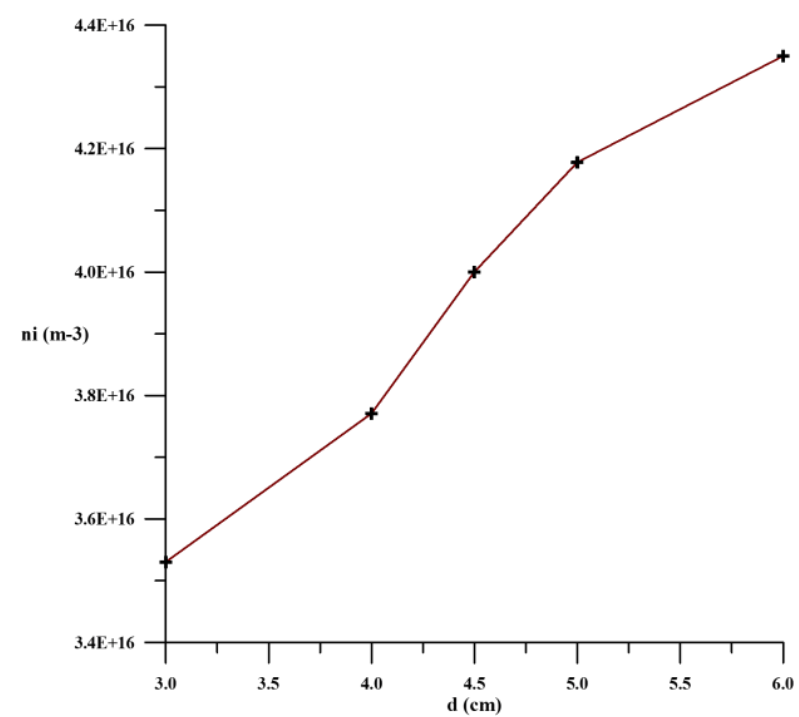

Fig. (8): Variation of ion density as a function of electrodes separation.

Silver nanoparticles are widely used in surface coating and material sciences due to their high conductivity and chemical inertness. DC magnetron sputtering has long been used to fabricate nanostructured coating, thin films and nanoparticles of various materials [16].

In this work, the formation of $\mathrm{Ag}$ nanoparticles on the glass substrate are investigated using DC magnetron sputtering Fig.(1) under different values of electrodes separation and sputtering currents.

To study the dependence of morphological properties for silver deposition on electrode distances using the atomic force microscope (AFM), a series of $\mathrm{Ag}$ sputtering particles on the glass substrate were prepared at a constant deposition time of $30 \mathrm{~s}$ with different values of sputtering currents.

The surface morphologies of $(20,30,40,50$ and 60) $\mathrm{mA}$ sputtering currents, $I_{d}$, for different electrodes separation $d(3,4,4.5,5$ and 6) $\mathrm{cm}$ are shown in Fig.(9). These images clearly show the nanostructured nature of $\mathrm{Ag}$ deposited and how it is changed with current and distance values. 

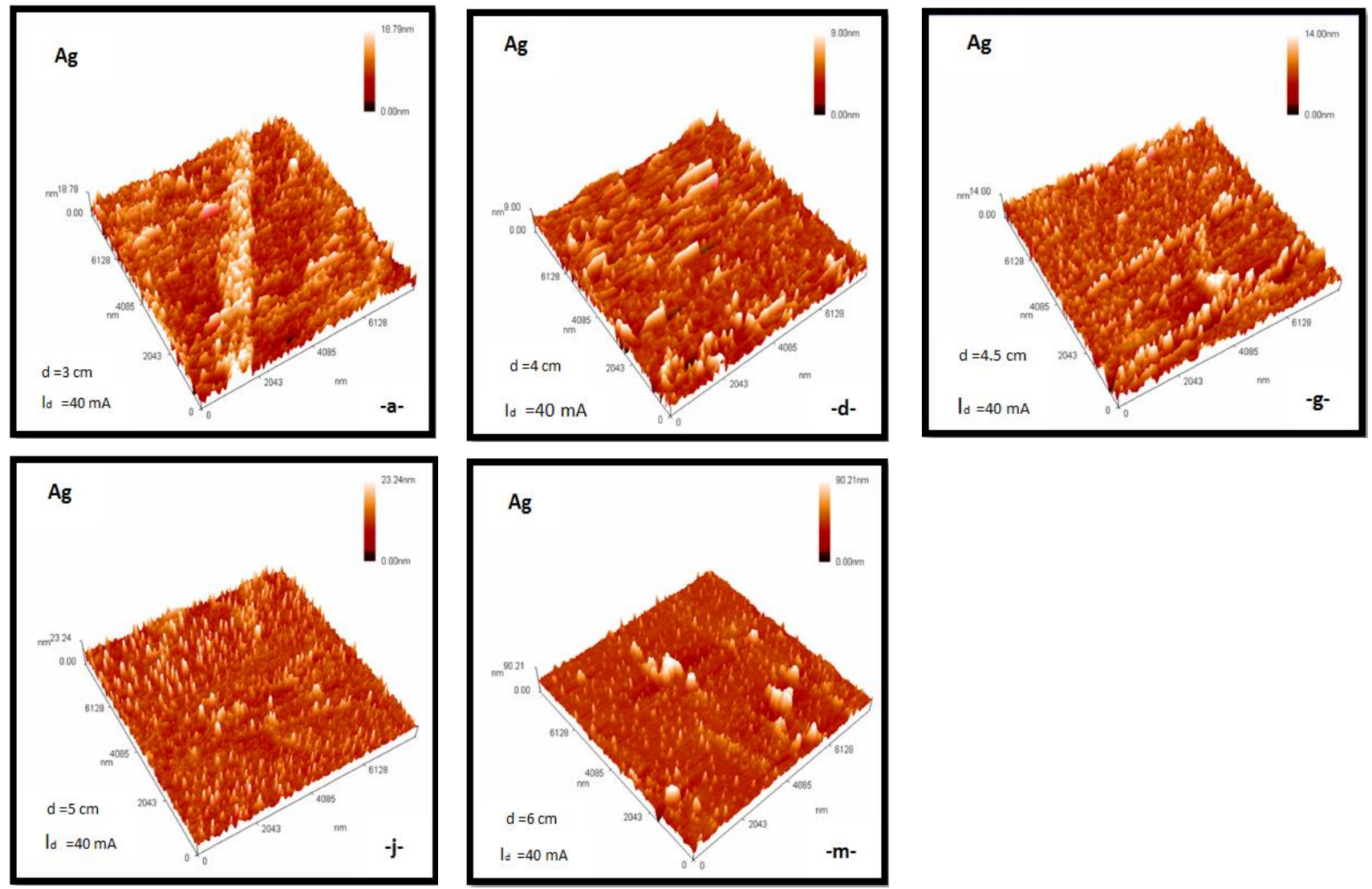

Fig.(9): Shows 3D images from the results of AFM using Ag target for different electrodes separation at Id $=40 \mathrm{~mA}$.

The variation of average grain diameter and average grain height as a function of electrode distance with different sputtering current values which obtained from the AFM images are presented in Fig.(10) and Fig.(11) respectively.

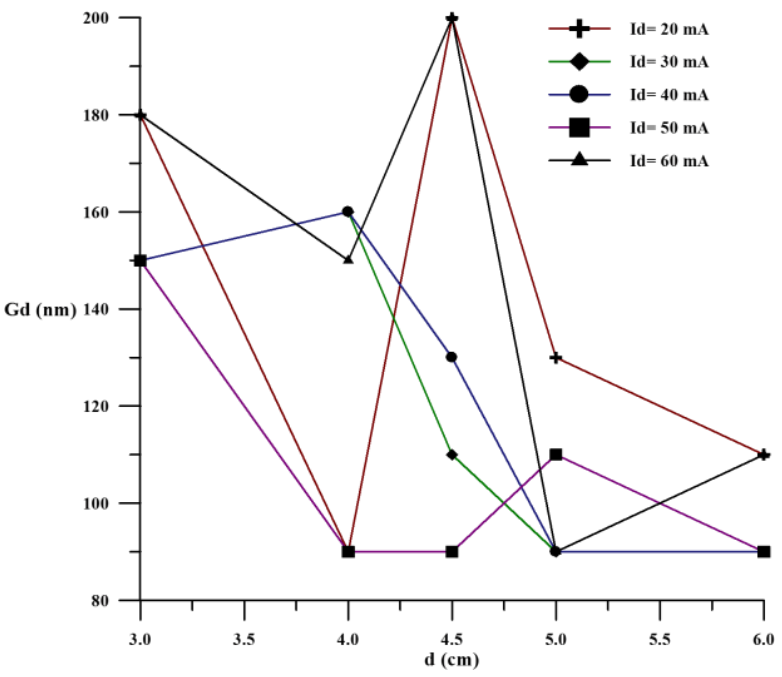

Fig.(10): Variation of particles grain diameter as a function of electrodes separation at different sputtering current.

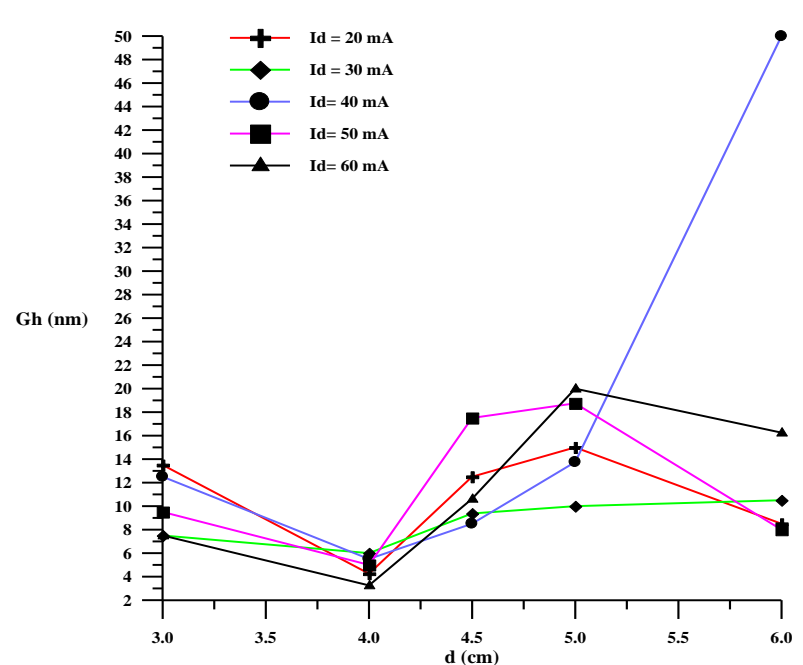

Fig.(11): Variation of particles grain height as a function of electrodes separation at different sputtering currents.

As one can see in Fig.(10) and Fig.(11), the increase of electrodes separation value caused the increases and decreases in the values of grain diameter and height. This is due to the changes of plasma parameters. In Tables (1) 
and (2) shows the maximum and minimum grain diameter and height at $\mathrm{I}_{d}=40 \mathrm{~mA}$.

Table (1)

Maximum and minimum grain diameter at $I_{d}=40 \mathrm{~mA}$.

\begin{tabular}{|c||c|c||c||}
\hline $\mathbf{G}_{\mathbf{d}}(\mathbf{n m})$ & $\mathbf{d}(\mathbf{c m})$ & $\mathbf{T}_{\mathbf{e}}(\mathbf{e V})$ & $\mathbf{n}_{\mathbf{i}}\left(\mathbf{m}^{\mathbf{- 3}}\right)$ \\
\hline \hline 160 & 4 & 4.4 & $3.7709 \times 10^{16}$ \\
\hline \hline \multirow{2}{*}{90} & 5 & 4.13 & $4.1777 \times 10^{16}$ \\
& 6 & 4 & $4.3435 \times 10^{16}$ \\
\hline
\end{tabular}

Table (2)

Maximum and minimum grain height at $I_{d}=40 \mathrm{~mA}$.

\begin{tabular}{|c|c||c||c|}
\hline $\mathbf{G}_{\mathbf{h}}(\mathbf{n m})$ & $\mathbf{d}(\mathbf{c m})$ & $\mathbf{T}_{\mathbf{e}}(\mathbf{e V})$ & $\mathbf{n}_{\mathbf{i}}\left(\mathbf{m}^{\mathbf{3}}\right)$ \\
\hline \hline 50 & 6 & 4 & $4.3435 \times 10^{16}$ \\
\hline \hline 5.5 & 4 & 4.4 & $3.7709 \times 10^{16}$ \\
\hline
\end{tabular}

From Table (1) the reason for these different values of grain diameter is due to the changes of plasma parameters. The temperature of electron at a maximum grain diameter is slightly greater than the temperature of electron at a minimum grain diameter. Also, it is notice that there are two minimum grain diameter at $\mathrm{d}=5 \mathrm{~cm}$ and $6 \mathrm{~cm}$. In Table (2) the temperature of electron at a minimum grain height is slightly greater than at maximum.

\section{4- Conclusions}

1-The relation between cathode voltage and anode current as a function of discharge current is directly proportional.

2-By using of DC plasma sputtering techniques, the choice of suitable operational parameters can produce a coater sample with grain of required size and other morphology properties.

3-For different discharge current, the relation of grain diameter and grain height as a function of electrodes separation is nonlinear.

4-The relation between temperature of electron and electrodes separation is inversely proportional, while the density of ions and electrodes separation is directly proportional.

5-As the temperature of electron increased, the values of grain diameter is increased while the grain height decreased.
6-For all sputtering current, the minimum grain height at $\mathrm{d}=4 \mathrm{~cm}$ and the maximum grain height at $\mathrm{d}=5 \mathrm{~cm}$.

\section{References}

[1] Heimann R. B., "Plasma-spray coating principles and applications", $\mathrm{VCH}$, Germany, 1996.

[2] Phelps A.V., "Abnormal glow discharge in Ar experiments and models plasma sources", Sci.Technol.10, 329, 2001.

[3] Laroussi M. "Non-thermal decontamination of biological media by atmospheric pressure plasma review, analysis and prospects", IEEE Trans. plasma sci., 30, 1409, 2002.

[4] You S.J., Park G.Y., Kown J.H., Kim J.H. and Chang H.Y., "Evolution of electron temperature in low pressure magnetized capacitive plasma", Appl. Phys. Lett., 96, 101504, 2010.

[5] Chen F.F., "Industrial applications of lowtemperature plasma physics", Phys. Plasma 2(6), 2164, 1995.

[6] Dolan T.J., "Review article: Magnetic electrostatic plasma confinement; Plasma physics and controlled fusion", 36, 1539, 1994.

[7] Hoiierweger R., Holec D., Paulitsch J., Rachbauer R., Polcik P. and Mayrhofer P.H., "Magnetic field strength influence on the reactive magnetron sputter deposition of $\mathrm{Ta}_{2} \mathrm{O}_{5}$ ", J. Phys. D: Appl. Phys., 46, 335203, 2013.

[8] Borah S. M., Pal A. R., Bailung H. and Chutia J., "Effect of Ex B electron drift and plasma discharge in $\mathrm{dc}$ magnetron sputtering plasma", Chin. Phys. B, 20, 014701, 2011.

[9] Lee Y.S., Winkler M.T., Siah S.C., Brandt R. and Buonassis T., "Hall mobility of cuprous oxide thin films deposited by reactive direct-current magnetron sputtering", Applied physics Letters, 98, 192115, 2011.

[10] Kong J., Shen H., Chen B., Li Z., Shi W., Yao W. and Oi Z., "The abnormal structure of nanocrystalline titanium films prepared by d.c. sputter". Thin solid films, 207, 51, 1999. 
[11] Lieberman M.A. and Lichtenberg A.J., "Principles of plasma discharge and materials processing", John Wiley \&Sons, Inc, N.Y., 1994.

[12] Baranov O., Romanov M., Wolter M., Kumar S., Zhong X. and Ostrikov K., "Low-pressure planar magnetron discharge for surface deposition and nanofabrication" Physics of plasma 17, 053509, 2010.

[13] Kelly P.J. and Amell R.D., "Magnetron sputtering: a review of recent development and applications", Vacuum 56,159-172, 2000.

[14] Raman P., Shchlkanov I.A., McLain J. and Ruzic D.N., "High power pulsed magnetron sputtering: A method to increase deposition rate", J. Vac. Sci. Technol. A33(3), 031304-1, 2015.

[15] Bohm D., Burhop E.H.S. and Massey H.S.W., "The characteristics of electrical discharge in magnetic fields", Ed. by A. Guthrie and R.K. Wakerling (M.Graw. Hill, New York, 1949).

[16] Xin Z., Xiao-Hui S. and Dian-Lin Z., "Thickness dependence of grain size and surface roughness for $\mathrm{dc}$ magnetron sputtered Au films", chin. phys. B, 19, 086802, 2010.

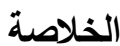

تم في هذا العمل، دراسة تأثثر المسافة بين القطبين على

معلمات البلازما وخصائص اشكال سطح النموذج المطلي

بالفضة باستعمال مصدر للتزذيذ البلازمي للتفريغ عند

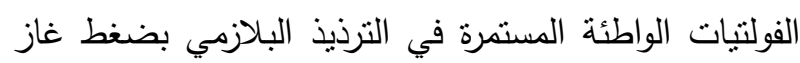

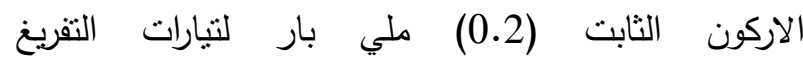

(20,30,40,50,60) ملي امبير لعدة مسافات بين القطبين (3,4,4.5,5,6)

يتكون مصدر التزذيذ البلازمي من حجرة اسطوانية تحنوي

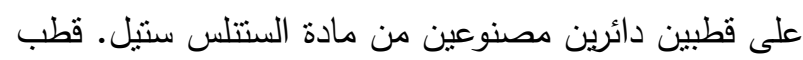

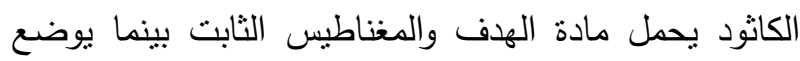
النموذج الزجاجي لطلائه على قطب الانود.

عوامل البلازما، درجة حرارة الالكترون وكثافة الايونات تن

تحديد باستعمال مجس لانكمور الاسطواني المنفرد وايضا
درسن خصنائ اثكال سطوح النعاذج المطلية بواسطة

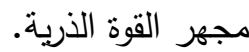

أوضحت نتائج هذا البحث زيادة خطية في كثافة الايونات

ونقصان بدالة أسية في درجة حرارة الالكترون بزيادة المسافة

بين القطبين. كما ان العلاقة بين معدل قطر الحبه دران الحبية

وارتفاعها كدالة غير خطية للمسافة بين القطبين. اقل معدل

قطر الحبيبة وارتفاعها هو (90) نانومتر عند المسافة (4)سم

وبتيار تفريغ (40) ملي امبير ، واقل معدل ارتفاع الحبيبة هو هو

(5.5) نانومتز بنفس المسافة بين القطبين وتيار التفريغ.

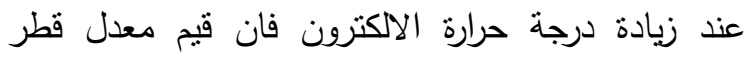

الحبيية يزداد ويقل ارتفاعها. 